|| ISSN(online): 2589-8698 || ISSN(print): 2589-868X || International Journal of Medical and Biomedical Studies

Available Online at www.ijmbs.info

PubMed (National Library of Medicine ID: 101738825)

Index Copernicus Value 2018: 75.71

Original Research Article

Volume 3, Issue 5; May: 2019; Page No. 09-11

\title{
ROLE OF CT SCAN IN DIAGNOSIS OF ACUTE APPENDICITIS
}

\author{
Saurabh ${ }^{1}$, Deepak Meena ${ }^{2}$, G. L. Meena ${ }^{3}$ \\ ${ }^{1,2}$ Resident, ${ }^{3}$ Senior Professor \\ ${ }^{1,3}$ Department of Radiodiagnosis, SP Medical College \& Associate Group of PBM Hospitals, Bikaner. \\ ${ }^{2}$ Mahatma Gandhi Dental College, Jaipur.
}

Article Info: Received 10 April 2019; Accepted 29 April. 2019

Cite this article as: S., Meena, D., \& Meena, G. L. (2019). ROLE OF CT SCAN IN DIAGNOSIS OF ACUTE APPENDICITIS. International Journal of Medical and Biomedical Studies, 3(5).

DOI: https://doi.org/10.32553/ijmbs.v3i5.231

Address for Correspondence: Deepak Meena, Resident, Mahatma Gandhi Dental College, Jaipur

Conflict of interest: No conflict of interest.

\begin{abstract}
Background: To evaluate the diagnostic accuracy of the spiral-CT in patients with clinically suspected acute appendicitis.

Methods: Appendiceal spiral-CT was performed in 50 patients ( 21 women and 29 men) with clinically suspected acute appendicitis. Scans were obtained from the L4 level to the symphysis pubis using $5 \mathrm{~mm}$ collimation without i.v., oral, or rectal contrast material. Prospective diagnoses based on CT findings were compared with histopathological results

Results: In our study appendix diameter test sensitivity was $97.56 \%$, specificity was $77.78 \%$, positive predictive value was $95.27 \%$, negative predictive value was $87.50 \%$ and diagnostic accuracy was $94.00 \%$.

Conclusion: The accuracy of computed tomography in diagnosing acute appendicitis was high. The results emphasize the role of computed tomography as an accurate modality in daily routine diagnostics for acute appendicitis in all clinical emergency settings.
\end{abstract}

Key words: Appendicitis, CT scan, Accuracy.

\section{Introduction:}

Appendicitis should be considered in any person with undiagnosed abdominal pain. The incidence peaks between the ages 15 and 24 . The concept that right lowers quadrant pain in women of childbearing age is more complex clinical problem than in men and they historically had higher rates of negative laparotomy. ${ }^{1}$ Anderson reported decreased diagnostic accuracy for appendicitis among women, particularly in the third decade of life. ${ }^{2}$ Clinical diagnosis of appendicitis is usually made on the basis of history, physical examination and laboratory studies but a variety of approaches have been used for diagnosis including ultrasound, helical computerized tomography (CT), clinical scoring systems, and neural network. However, approximately20-35\% of patients with suspected appendicitis present with diagnostic dilemma mainly in the extremes of life, ovulating females and young children. ${ }^{4}$
Aim of this study was to to evaluate the diagnostic accuracy of the spiral-CT in patients with clinically suspected acute appendicitis.

\section{METHODS}

Appendiceal spiral-CT was performed in 50 patients (21 women and 29 men) with clinically suspected acute appendicitis. Scans were obtained from the L4 level to the symphysis pubis using $5 \mathrm{~mm}$ collimation without i.v., oral, or rectal contrast material. Prospective diagnoses based on CT findings were compared with histopathological results and clinical follow-up.

The criteria used to diagnose acute appendicitis were: (a) a thickened appendix of more than $7 \mathrm{~mm}$ or (b) inflammatory changes in the periappendiceal fat.

If the CT findings were negative for acute appendicitis and surgery not performed, the results were 
correlated with other corroborating diagnostic RESULTS investigations or clinical follow-up

Table 1 : Diameter of appendix in CT scan

\begin{tabular}{|l|l|l|}
\hline Diameter of appendix in CT scan & No. of patients & Percentage \\
\hline Diameter <6 MM & 8 & $16.00 \%$ \\
\hline Diameter <6 MM & 42 & $84.00 \%$ \\
\hline Mean diameter of appendix in CT scan & $7.61 \pm 1.43 \mathrm{~mm}$ & \\
\hline
\end{tabular}

In our study mean diameter of appendix in CT scan was $7.61 \pm 1.43 \mathrm{~mm}$. $<6 \mathrm{~mm}$ diameter was consider as normal.

Table 2 : Correlation between appendix diameter and histopathological findings

\begin{tabular}{|l|l|l|l|}
\hline \multirow{2}{*}{ Appendix diameter } & \multicolumn{2}{|l|}{ Histopathology } & \multirow{2}{*}{ Total } \\
\cline { 2 - 4 } & Normal & Abnormal & \\
\hline$>6 \mathrm{~mm}$ & 2 & 40 & 42 \\
\hline$\leq 6 \mathrm{~mm}$ & 7 & 1 & 8 \\
\hline Total & 9 & 41 & 100 \\
\hline
\end{tabular}

In our present study $94 \%$ of the diameter of appendix test are true whether level was raised or it was normal only $6 \%$ of the tests done for diameter of appendix done estimation gave false report.

Table 3 : Diagnostic accuracy of appendix diameter

\begin{tabular}{|l|l|}
\hline Sensitivity & $97.56 \%$ \\
\hline Specificity & $77.78 \%$ \\
\hline Positive predictive value & $95.27 \%$ \\
\hline Negative predictive value & $87.50 \%$ \\
\hline Diagnostic accuracy & $94.00 \%$ \\
\hline
\end{tabular}

In our study appendix diameter test sensitivity was $97.56 \%$, specificity was $77.78 \%$, positive predictive value was $95.27 \%$, negative predictive value was $87.50 \%$ and diagnostic accuracy was $94.00 \%$.

\section{DISCUSSION}

Appendicitis needs to be considered in the differential diagnosis of almost every patient with acute abdominal pain ${ }^{5}$. Early diagnosis remains the most important goal in these patients and is made in most cases based only on history and clinical examination. The typical presentation begins with periumbilical pain due to irritation of visceral nerves. Followed by anorexia and nausea. The pain then localizes to right lower quadrant as inflammatory process involves parietal peritoneum overlying appendix. Fever ensues, followed by development of leukocytosis. 
In present study, out of total 100 patients $82.00 \%$ were have positive HPE finding and $18.00 \%$ were have negative HPE finding. Similar result were observed by Rasoul,et $\mathrm{al}^{6}$ and Kimaro,S.et al ${ }^{7}$.

\section{CONCLUSION}

The accuracy of computed tomography in diagnosing acute appendicitis was high. The results emphasize the role of computed tomography as an accurate modality in daily routine diagnostics for acute appendicitis in all clinical emergency settings.

\section{REFERENCES}

1. Hoffmann J. Rasmussen O. Aids in the diagnosis of acute appendicitis. Br J surg 1989; 76:774-779

2. John $H$, Neff $U$, Kelemen $M$. Appendicitis diagnosis today: clinical and ultrasonic deductions. World J surg1993; 17:243-249

3. Jones PF. Suspected acute appendicitis: trends in management over 30 years. $\mathrm{Br} J$ surg2001; 88:1570-1577
4. Lee SL, Walsh AJ, Ho HS, computed tomography and ultrasonography do not improve and may delay the diagnosis and treatment of acute appendicitis. Arch surg2001; 136:556-561

5. DouglasS.smink/Davidl.soybel; Appendix and appendectomy; In Maingot's abdominal operations; Michel J, Zinner (Ed); 11th ed; McGraw-Hill; 2007; pp. 589-608.

6. Rasoul, A.,Negin F.,Tahmineh, M., SeyedMohammad, F., et al. Low diagnostic values of ultrasonoqraphy and negative appendectomy: Still a major problem in university hospitals. Medical journal of the Islamic Republic of Iran 2011 Feb; 24 (4):200-207

7. Kimaro,S. Correlation of ultrasound,clinical and surgical findings of suspected acute appendicitis in KNH. MMed dissertation. Universlty' of Nairobi 2011. 